\title{
Effects of dietary mannanoligosaccharide on performance of Japanese quail affected by aflatoxicosis
}

\author{
H. Oguz ${ }^{1 \#}$ and S.S. Parlat ${ }^{2}$ \\ ${ }^{1}$ Department of Pharmacology and Toxicology, Faculty of Veterinary Medicine, Selcuk University, Kampus, Konya, \\ Turkey \\ ${ }^{2}$ Department of Animal Science, Faculty of Agriculture, Selcuk University, Kampus, Konya, Turkey
}

\begin{abstract}
The potential of the yeast component, mannanoligosaccharide (MOS) to ameliorate the effects of aflatoxicosis was examined in growing Japanese quail. The product was incorporated in the diet at $1 \mathrm{~g} / \mathrm{kg}$ and was evaluated for its ability to reduce the deleterious effects of $2 \mathrm{mg}$ total aflatoxin (AF; $82.30 \% \mathrm{AFB}_{1}$, $2.06 \% \mathrm{AFB}_{2}, 7.68 \% \mathrm{AFG}_{1}$ and $7.96 \% \mathrm{AFG}_{2}$ )/kg diet on Japanese quail chicks from 10 to 45 days of age. Forty 10-d old Japanese quail chicks were assigned in a 2x2 factorial arrangement of treatments to four groups (Control, AF, MOS, AF plus MOS), each consisting of 10 quails. The addition of AF alone significantly decreased feed consumption and body weight gain from the first week onwards. A significant adverse effect of AF on the feed conversion ratio was also observed from week 4 onwards. The addition of MOS to the AF-containing diet significantly reduced these adverse effects of AF on feed consumption, body weight gain and feed conversion ratio. The cumulative body weight gain was $22.0 \%$ lower in the quails consuming a diet containing AF without MOS as compared to the control group. However, it was only $2.3 \%$ lower that the control in the birds fed the diet containing the AF plus MOS.
\end{abstract}

Keywords: Aflatoxin, mannanoligosaccharide, quail, preventive effect

\#Corresponding author. E-mail: haoguz@selcuk.edu.tr

\section{Introduction}

Aflatoxins (AF) are secondary toxic metabolites produced by fungi belonging to the genus Aspergillus, and can occur as natural contaminants of poultry feeds. Aflatoxins may cause serious economic losses in the poultry industry because they prevent birds from achieving optimum body weight gains (Oguz \& Kurtoglu, 2000). Aflatoxicosis in poultry also causes listlessness, anorexia with a lowered growth rate, poor feed utilisation, decreased egg production and increased mortality (Miazzo et al., 2000). In addition, anaemia (Oguz et al., 2000), reduction of the immune function (Oguz et al., 2003), hepatotoxicosis and heamorrhage (Ortatatli \& Oguz, 2001) are associated with aflatoxicosis.

Practical and cost-effective methods for the detoxification of AF-containing feeds and feedstuffs are in great demand. At the beginning of the 1990s, studies were conducted on adsorbent-based products to test their ability to detoxify feed contaminated with AF, and thus minimise aflatoxicosis in poultry (Peraica et al., 2002). However, the required high inclusion rates and potential interactions with feed nutrients are a cause of concern (Parlat et al., 1999; Miazzo et al., 2000).

Previous studies suggested that the best approach for decontamination would be biological degradation which would allow for the inactivation of AF under mild conditions without using harmful chemicals or causing significant losses in nutritive value and palatability of detoxified feeds and feedstuffs (Bata \& Lasztity, 1999). Recent biotechnological progress has opened new avenues for tackling this problem. Live yeast (Saccharomyces cerevisiae; SCE), initially used as a performance promoter in the early 1990s, was found to have beneficial effects on weight gain and immune responses in broilers exposed to AF (Stanley et al., 1993). Recent studies also showed significant improvements in symptoms associated with aflatoxicosis in quail chicks receiving SCE (Parlat et al., 2001; Yildirim \& Parlat, 2003).

The beneficial effects of SCE were attributed to mannan, which is an external component of the cell wall of SCE. Mannan was extracted, phosphorilated and the resultant mannanoligosaccharide (MOS) was used to remove/bind pathogenic bacteria in the intestine (Fairchild et al., 2001; Fernandez et al., 2002; Ceylan et al., 2003). This increased the intestinal absorption capacity for nutrients (Sonmez \& Eren, 1999) and improved immuno-modulation (Fritts \& Waldroup, 2003; Shashidhara \& Devegowda, 2003) in poultry. 
Although MOS was reported to have toxin-binding properties (Stanley, 2000), little information is available on the potential of MOS to detoxify AF (Devegowda et al., 1996).

The objective of this study was to observe the toxic effects of AF (2 mg/kg feed) on growth performance of Japanese quail and to evaluate the possible beneficial effects of dietary MOS on aflatoxicosis in Japanese quail, in order to develop a practical method for detoxifying AF.

\section{Materials and Methods}

In total, 40 unvaccinated Japanese quail (Coturnix coturnix japonica) chicks (10 day-old, 20 males and 20 females) were weighed, allocated randomly within sex to four experimental treatments, 10 quails per treatment and placed in individual cages (one quail per cage). The experimental design was a $2 \mathrm{x} 2$ factorial arrangement of treatments. The four experimental treatments were: 1) Control: a basal diet; 2) AF: basal diet plus $2 \mathrm{mg}$ total AF (composition given below)/kg diet; 3) MOS: basal diet plus $1 \mathrm{~g}$ mananoligosaccharide (MOS)/kg diet; 4) AF+MOS: basal diet plus $2 \mathrm{mg}$ AF plus $1 \mathrm{~g}$ MOS $/ \mathrm{kg}$ diet.

The birds received a basal diet (maize and soya bean based; $240.1 \mathrm{~g}$ crude protein/kg; $12.1 \mathrm{MJ}$ $\mathrm{ME} / \mathrm{kg}$ ), formulated to meet the NRC (1994) requirements of all nutrients including vitamins and minerals though without the addition of antibiotics, coccidiostats or growth promoters. The diet and water were available ad libitum and lighting was continuous. Before commencement of the trial the basal diet was proven to be clear of any detectable levels of residual AF (Howel \& Taylor, 1981; detection limit $1 \mu \mathrm{g} / \mathrm{kg}$ feed; recovery of the extraction method 95\%).

Aflatoxin was produced from Aspergillus parasiticus NRRL 2999 culture (USDA, Agricultural Research Service, Peoria, IL) through fermentation of rice by the method of Shotwell et al. (1966). Successfully fermented rice was then autoclaved to kill the fungus, dried and ground to a fine powder. The AF content in the rice powder was analysed by the method of Shotwell et al. (1966) and measured on a Thin Layer Chromatography (TLC)-Fluorometric Densitometer (Camag II, Basel, Switzerland) on the TLC spots (Plates from Merck; other equipment from Desega) using AF standards. The AF within the rice powder consisted of $82.3 \% \mathrm{AFB}_{1}, 2.06 \% \mathrm{AFB}_{2}, 7.68 \% \mathrm{AFG}_{1}$ and $7.96 \% \mathrm{AFG}_{2}$ (detection limit $1 \mu \mathrm{g} \mathrm{AF} / \mathrm{kg}$ rice powder; recovery of the extraction method $92 \%$ ). The rice powder was incorporated in the basal diet to provide the required concentration of $2 \mathrm{mg} \mathrm{AF} / \mathrm{kg}$ feed. The MOS extract (Bio-Mos ${ }^{\circledR}$; prepared from SCE) was provided by Alltech Inc. (KY, 40356, USA) and was supplemented at a level of $1 \mathrm{~g} / \mathrm{kg}$ of feed. The AF was incorporated into the mixed feed before MOS was added.

During the experiment the body weights of quails were assessed at 17, 24, 31, 38 and 45 days of age and mortality was recorded as it occurred. The feeds and feed residues were weighed on the same days as above to evaluate the feed consumption (FC) and feed conversion ratio (FCR). The feeding trial was terminated when the chicks reached 45 days of age. Data for FC, body weight gain (BWG) and FCR were grouped and expressed as mean \pm pooled standard errors of means. The results obtained were statistically analysed using Duncan's multiple range test (SPSS, 1999). Statistical significance is based on $\mathrm{P}<0.05$.

\section{Results}

Data presented in Tables 1, 2 and 3 show the effect of dietary treatments on FC, BWG and FCR, respectively. Feeding the diet with AF alone suppressed $(\mathrm{P}<0.05)$ the $\mathrm{FC}$ and BWG from the first week onwards compared to control diet. The adverse effect of AF on FCR was significant $(\mathrm{P}<0.05)$ in the second half of the trial period, with the peak in week 4, totally 7.81\% lower than the control. The addition of MOS to the AF-containing diet completely ameliorated the adverse effects of AF on FC, BWG and FCR. Compared to the control, the cumulative FC was depressed by $16.0 \%$ in the quail chicks consuming AF containing diet without MOS, but decreased only by $1.64 \%$ in the birds consuming AF plus MOS. Similarly, the overall BWG was lower ( $\mathrm{P}<0.05$ ) (by 22\%) in the AF-fed quails compared to the control, but it decreased by only $2.33 \%$ in the AF plus MOS-supplemented group, while the FCR was not affected (3.20 vs. 3.22). The supplementation of MOS to the AF-free diet increased the FC by $2.46 \%$ and BWG by $2.73 \%$, compared to the control, while the FCR was not affected. No mortalities occurred among the birds in all the groups. 
Table 1 Effect of mannanoligosaccharide (MOS; $1 \mathrm{~g} / \mathrm{kg}$ diet) on food consumption of Japanese quail receiving a diet containing $2 \mathrm{mg}$ total aflatoxin (AF)/kg diet between 10 and 45 days of age*

\begin{tabular}{ccccccccc}
\hline \multicolumn{7}{c}{ Treatment } & \multicolumn{7}{c}{ Feed consumption (g) } \\
\hline \multirow{2}{*}{ AF } & MOS & Week 1 & Week 2 & Week 3 & Week 4 & Week 5 & Wk 1 to 5 & Diff. \\
$(11)$ & $(18$ to 24) & $(25$ to 31) & (32 to 38) & (39 to 45) & (10 to 45) & (\%) \\
\hline- & - & $72.7 \pm 1.4^{\mathrm{a}}$ & $100.9 \pm 1.6^{\mathrm{a}}$ & $118.0 \pm 2.1^{\mathrm{ab}}$ & $132.2 \pm 1.9^{\mathrm{a}}$ & $130.3 \pm 2.0^{\mathrm{b}}$ & $554.2 \pm 3.6^{\mathrm{b}}$ & 0 \\
+ & - & $69.0 \pm 1.0^{\mathrm{b}}$ & $91.8 \pm 1.7^{\mathrm{b}}$ & $107.9 \pm 2.3^{\mathrm{c}}$ & $98.9 \pm 2.0^{\mathrm{b}}$ & $98.2 \pm 1.9^{\mathrm{c}}$ & $465.7 \pm 3.8^{\mathrm{c}}$ & -15.97 \\
- & + & $73.5 \pm 1.7^{\mathrm{a}}$ & $102.2 \pm 2.3^{\mathrm{a}}$ & $123.2 \pm 2.3^{\mathrm{a}}$ & $133.2 \pm 1.7^{\mathrm{a}}$ & $135.7 \pm 1.8^{\mathrm{a}}$ & $567.8 \pm 3.4^{\mathrm{a}}$ & +2.46 \\
+ & + & $70.4 \pm 0.9^{\mathrm{ab}}$ & $100.9 \pm 1.3^{\mathrm{a}}$ & $114.4 \pm 2.0^{\mathrm{b}}$ & $129.6 \pm 1.3^{\mathrm{a}}$ & $129.9 \pm 1.4^{\mathrm{b}}$ & $545.1 \pm 2.4^{\mathrm{b}}$ & -1.64 \\
\hline
\end{tabular}

* Values represent the mean \pm s.e.m. of four groups of 10 quail chicks;

${ }^{\mathrm{a}-\mathrm{c}}$ Means with no common superscripts differ at $\mathrm{P}<0.05$

Table 2 Effect of mannanoligosaccharide (MOS; $1 \mathrm{~g} / \mathrm{kg}$ diet) on body weight gain of Japanese quail receiving a diet containing $2 \mathrm{mg}$ total aflatoxin (AF)/kg diet between 10 and 45 days of age*

\begin{tabular}{|c|c|c|c|c|c|c|c|c|}
\hline \multicolumn{2}{|c|}{ Treatment } & \multicolumn{7}{|c|}{ Body weight gain (g) } \\
\hline $\mathrm{AF}$ & MOS & $\begin{array}{c}\text { Week } 1 \\
\text { (11 to } 17)\end{array}$ & $\begin{array}{c}\text { Week } 2 \\
\text { (18 to } 24)\end{array}$ & $\begin{array}{c}\text { Week } 3 \\
\text { (25 to 31) }\end{array}$ & $\begin{array}{c}\text { Week } 4 \\
\text { (32 to } 38) \\
\end{array}$ & $\begin{array}{c}\text { Week } 5 \\
\text { (39 to } 45) \\
\end{array}$ & $\begin{array}{l}\text { Wk } 1 \text { to } 5 \\
\text { (10 to } 45)\end{array}$ & $\begin{array}{l}\text { Diff. } \\
(\%)\end{array}$ \\
\hline- & - & $31.3 \pm 0.74$ & $34.4 \pm 0.96^{\mathrm{a}}$ & $35.9 \pm 0.73^{\mathrm{ab}}$ & $37.6 \pm 0.71^{\mathrm{ab}}$ & $34.3 \pm 0.51^{b}$ & $173.4 \pm 2.54^{\mathrm{b}}$ & 0 \\
\hline+ & - & $30.4 \pm 0.65$ & $30.8 \pm 0.74^{\mathrm{b}}$ & $32.0 \pm 0.80^{c}$ & $24.9 \pm 0.81^{\mathrm{c}}$ & $17.2 \pm 0.96^{c}$ & $135.2 \pm 0.97^{\mathrm{c}}$ & -21.99 \\
\hline- & + & $31.4 \pm 0.69$ & $34.7 \pm 1.07^{\mathrm{a}}$ & $36.9 \pm 0.92^{\mathrm{a}}$ & $38.8 \pm 1.01^{\mathrm{a}}$ & $36.3 \pm 0.68^{\mathrm{a}}$ & $178.18 \pm 2.49^{\mathrm{a}}$ & +2.73 \\
\hline+ & + & $30.8 \pm 0.68$ & $33.6 \pm 1.05^{\mathrm{a}}$ & $35.0 \pm 0.89^{b}$ & $36.1 \pm 0.64^{\mathrm{b}}$ & $33.9 \pm 0.78^{b}$ & $169.3 \pm 1.79^{\mathrm{b}}$ & -2.33 \\
\hline
\end{tabular}

* Values represent the mean \pm s.e.m. of four groups of 10 quail chicks;

${ }^{\mathrm{a}-\mathrm{c}}$ Means with no common superscripts differ at $\mathrm{P}<0.05$

Table 3 Effect of mannanoligosaccharide (MOS; $1 \mathrm{~g} / \mathrm{kg}$ diet) on feed conversion ratio in Japanese quail receiving a diet containing $2 \mathrm{mg}$ total aflatoxin (AF)/kg diet between 10 to 45 days of age*

\begin{tabular}{ccccccccc}
\hline \multicolumn{7}{c}{ Treatment } & \multicolumn{7}{c}{ Feed conversion ratio (g feed/g body weight gain) } \\
\hline & & Week 1 & Week 2 & Week 3 & Week 4 & Week 5 & Wk 1 to 5 & Diff. from \\
AF & MOS & $(11$ to 17) & $(18$ to 24) & $(25$ to 31) & $(32$ to 38) & (39 to 45) & (10 to 45) & control (\%) \\
\hline- & - & $2.34 \pm 0.07$ & $2.96 \pm 0.10$ & $3.31 \pm 0.11$ & $3.53 \pm 0.05^{\mathrm{b}}$ & $3.80 \pm 0.08^{\mathrm{b}}$ & $3.20 \pm 0.09^{\mathrm{b}}$ & 0 \\
+ & - & $2.28 \pm 0.04$ & $2.99 \pm 0.08$ & $3.40 \pm 0.13$ & $4.01 \pm 0.14^{\mathrm{a}}$ & $5.94 \pm 0.48^{\mathrm{a}}$ & $3.45 \pm 0.04^{\mathrm{a}}$ & +7.81 \\
- & + & $2.35 \pm 0.08$ & $2.96 \pm 0.09$ & $3.35 \pm 0.10$ & $3.45 \pm 0.08^{\mathrm{b}}$ & $3.75 \pm 0.03^{\mathrm{b}}$ & $3.19 \pm 0.05^{\mathrm{b}}$ & -0.31 \\
+ & + & $2.29 \pm 0.04$ & $3.02 \pm 0.08$ & $3.29 \pm 0.12$ & $3.61 \pm 0.09^{\mathrm{b}}$ & $3.86 \pm 0.10^{\mathrm{b}}$ & $3.22 \pm 0.04^{\mathrm{b}}$ & +0.63 \\
\hline
\end{tabular}

* Values represent the mean \pm s.e.m. of four groups of 10 quail chicks;

${ }^{\mathrm{a}-\mathrm{c}}$ Means with no common superscripts differ at $\mathrm{P}<0.05$

\section{Discussion}

The most prevalent symptom of aflatoxicosis in poultry and livestock is reduced growth rate and thus a poor performance. The reduced BWG would lead to economic losses and also severe AF-dependent diseases in poultry flocks. In this study, quails consuming $2 \mathrm{mg} / \mathrm{kg}$ AF-containing diet showed a poor body weight gain $(\mathrm{P}<0.05)$. Aflatoxin also caused significant ( $\mathrm{P} 0.05$ ) suppression on FC and FCR values. These effects 
observed in performance of birds were noticed from week 1 onwards and progressively increased until the end of the experimental period. The adverse effects of AF on FC, BWG and FCR are probably due to anorexia, listlessness, inhibition of protein synthesis and lipogenesis (Oguz \& Kurtoglu 2000; Oguz et al., 2000; Parlat et al., 2001). Impaired liver functions and carbohydrate utilisation mechanisms may also have affected the growth performance and general health of the birds (Miazzo et al., 2000; Ortatatli \& Oguz, 2001). The results of this study agree with that of other reports on AF (1-4 mg/kg) performed in the quail (Sadana et al., 1992; Parlat et al., 1999).

Feeds contaminated with AF pose a health risk to animals and, as a consequence, may cause serious economic losses due to the lower efficacy in animal production. Producers and scientists aim at developing effective decontamination technology dealing with this feed-borne toxin. Decontamination procedures have focused on degrading, destroying, inactivating or removing AF by physical, chemical and biological methods. Recently, researchers have directed efforts toward finding effective means of the biological degradation of AF. In this context, live yeast (SCE) was used in controlling the severity of AF and provided significant improvements (Stanley et al., 1993; Parlat et al., 2001). The beneficial effects of SCE have been attributed to MOS and this complex sugar was extracted from the cell walls of SCE. As seen in Tables 1, 2 and 3, the addition of MOS (1 g/kg; from SCE) to an AF-containing diet significantly ameliorated the adverse effects of AF on performance parameters (FC, BWG and FCR) in quails $(\mathrm{P}<0.05)$. Previous studies (Raju \& Devegowda, 2000; Aravind et al., 2003) reported that similar improvements were observed by modified (esterified) glucomannan, which is a mannan-glucan combination, in aflatoxicosis cases in broilers.

The beneficial counteraction of MOS on AF molecules in the gastrointestinal tract have been clearly seen in our study as predicted. The role of MOS in AF detoxification might be attributed to a selective binding capacity for AF molecules (Devegowda et al., 1996), to modulate the immune response (Fairchild et al., 2001; Fernandez et al., 2002; Shashidhara \& Devegowda, 2003) and to provide nutrients that are beneficial to gut flora, thus improving animal production (Fritts \& Waldroup, 2003). The single additions of MOS to an AF-free diet did not produce any negative changes compared to the control. Moreover, MOSalone provided additional improvements in the performance of birds $(\mathrm{P}<0.05)$. This supported other reports (Stanley \& Sefton, 2000; Parlat et al., 2001) that showed that MOS, like SCE, was inert and non-toxic.

\section{Conclusions}

These results clearly demonstrated that the growth performances (FC, BWG and FCR) of quails were negatively affected by the feeding of an AF ( $2 \mathrm{mg} / \mathrm{kg}$ )-containing diet for five weeks and that the addition of MOS $(1 \mathrm{~g} / \mathrm{kg})$ to the AF-containing diet significantly ameliorated the adverse effects of AF on performance. These improvements obtained in this study contribute to a safe and practical decontamination procedure and progress toward a solution to the AF problem in poultry, when used in conjunction with other AF prevention practices.

\section{References}

Aravind K.L., Patil, V.S., Devegowda, G., Umakhanta, B. \& Ganpule, S.P., 2003. Efficacy of esterified glucomannan to counteract mycotoxicosis in naturally contaminated feed on performance and serum biochemical, hematological parameters in broilers. Poult. Sci. 82, 571-576.

Bata, A. \& Lasztitiy, R., 1999. Detoxification of mycotoxin-contaminated food and feed by microorganisms. Trends in Food Sci. Technol. 10, 223-228.

Ceylan, N., Ciftci, I. \& Ilhan, Z., 2003. The Effects of Some Alternative Feed Additives for Antibiotic Growth Promoters on the performance and gut flora of broiler chicks. Turk. J. Vet. Anim. Sci. 27, 727733.

Devegowda, G., Aravind, B.I.R. \& Morton, M.G., 1996. Saccharomyces cerevisiae and mannanoligosaccharide to counteract aflatoxicosis in broilers. Proc. Aust. Poult. Sci. Symp. Sydney. pp. 103106.

Fairchild, A.S., Grimes, J.L., Jones, F.T., Wineland, M.J., Edens, F.W. \& Sefton, A.E., 2001. Effects of hen age, Bio-Mos, and flavomycin on poult susceptibility to oral Escherichia coli challenge. Poult. Sci. 80, 562-571.

Fernandez, F., Hinton, M. \& Gils, B.V., 2002. Dietary mannan-oligosaccharides and their effect on chicken caecal microflora in relation to Salmonella enteritidis colonization. Avian Pathol. 31,49-58. 
Fritts, C.A. \& Waldroup, P.W., 2003. Evaluation of Bio-Mos ${ }^{\circledR}$ mannan oligosaccharide as a replacement for growth promoting antibiotics in diets for turkeys. Int. J. Poult. Sci. 2, 19-22.

Howel, M.V. \& Taylor, P.W., 1981. Determination of aflatoxins, ochratoxin A, and zearalenone in mixed feeds, with detection by thin layer chromatography or high performance liquid chromatography. JAOAC. 64, 1356-1363.

Miazzo, R., Rosa, C.A., Carvalho, E.C., Magnoli, C., Chiacchiera, S.M., Palacio, G., Saenz, M., Kikot, A., Basaldella, E. \& Dalcero, A., 2000. Efficacy of synthetic zeolite to reduce the toxicity of aflatoxin in broiler chicks. Poult. Sci. 79, 1-6.

NRC, 1994. Nutrient Requirements of Poultry (9th ed.). National Academy Press, Washington D.C. pp. 4445.

Oguz, H. \& Kurtoglu, V., 2000. Effect of clinoptilolite on fattening performance of broiler chickens during experimental aflatoxicosis. Br. Poult. Sci. 41, 512-517.

Oguz, H., Kececi, T., Birdane, Y.O., Onder, F. \& Kurtoglu, V., 2000. Effect of clinoptilolite on serum biochemical and haematological characters of broiler chickens during experimental aflatoxicosis. Res. Vet. Sci. 69, 89-93.

Oguz, H., Hadimli, H.H., Kurtoglu, V. \& Erganis, O., 2003. Evaluation of humoral immunity of broilers during chronic aflatoxin (50 and $100 \mathrm{ppb}$ ) and clinoptilolite exposure. Rev. Med. Vet. 154, 483-486.

Ortatatli, M. \& Oguz, H., 2001. Ameliorative effects of dietary clinoptilolite on pathological changes in broiler chickens during aflatoxicosis. Res. Vet. Sci. 71, 59-66.

Parlat, S.S., Yildiz, A.O. \& Oguz, H., 1999. Effect of clinoptilolite on fattening performance of Japanese quail (Coturnix coturnix japonica) during experimental aflatoxicosis. Br. Poult. Sci. 40, 495-500.

Parlat, S.S., Ozcan, M. \& Oguz, H., 2001. Biological suppression of aflatoxicosis in Japanese quail (Coturnix coturnix japonica) by dietary addition of yeast (Saccharomyces cerevisiae). Res. Vet. Sci. 71, 207-211.

Peraica, M., Domijan A., Jurjevic, C. \& Cvetjkovic, B., 2002. Prevention of exposure to mycotoxins from food and feed. Archives Hig Rada Toks. 53, 229-237.

Raju, M.V.L.N. \& Devegowda, G., 2000. Influence of esterified-glucomannan on performance and organ morphology, serum biochemistry and haematology in broilers exposed to individual and combined mycotoxicosis (aflatoxin, ochratoxin and T-2 toxin). Br. Poult. Sci. 41, 640-650.

Sadana, J.R., Asrani, P.K. \& Pandita, A., 1992. Effect of dietary aflatoxin B $_{1}$ on the growth response and haematologic changes of young Japanese quail. Mycopathol. 118, 133-137.

Shashidhara, R.G. \& Devegowda, G., 2003. Effect of dietary mannan oligosaccharide on broiler breeder production traits and immunity. Poult. Sci. 82, 1319-1325.

Shotwell, O.L., Hesseltine, C.V., Stubblefield, R.D. \& Sorenson, W.G., 1966. Production of aflatoxin on rice. Appl. Microbiol. 14, 425-429.

Sonmez, G. \& Eren, M., 1999. Effects of supplementation of zinc bacitracin, mannanoligosaccharide and probiotic into broiler feeds on the morphology of the small intestine. U. U. Vet. Fak. Derg. 18, 125138.

SPSS, 1999. SPSS/PC+V.2.0. Base Manuel for the IBM PC/XT/AT and PS/2. Marija and Morusis, SPSS Inc. 444 N. Michigan Avenue, Chicago, IL, 60611.

Stanley, V.G., Ojo, R., Woldensenbet, S. \& Hutchinson, D.H., 1993. The use of Saccharomyces cerevisiae to suppress the effect of aflatoxicosis in broiler chicks. Poult. Sci. 72, 1867-1872.

Stanley, V.G., 2000. Interfacing disease, nutrition and immunity (Ask the Expert in 2 CD), Alltech Inc, KY 40356. (Corpmedia@alltech-bio.com).

Stanley, V.G. \& Sefton, A.E., 2000. Egg serum cholesterol as influenced by mannan oligosaccharide and aflatoxin. In: Egg Nutrition and Biotechnology. Eds. Jim, J.S. \& Nakai, W., Guenter. CAB Int.

Yildirim, I. \& Parlat, S.S., 2003. Effects of dietary addition of live yeast (Saccharomyces cerevisiae) on hatching traits, testis and ovary weights of Japanese quail (Coturnix coturnix japonica) in aflatoxicosis. Archiv fur Geflugelk. 67, 208-211. 